\title{
Study of Ukrainian Polar Explorers' Psychological Readiness for Extreme Environments at the Antarctic Station
}

\author{
Olena Miroshnychenko ${ }^{1}$, Igor Pasichnyk ${ }^{2}$, Alexander Voznyuk ${ }^{3}$, Serhii Kubitskyi ${ }^{4}$, Marina Roganova ${ }^{5}$, \\ Hanna Tsvietkova ${ }^{6}$, Inna Shorobura ${ }^{7}$, Ihor Bloshchynskyi ${ }^{8, *}$ \\ ${ }^{1}$ Department of Pedagogy, Professional Education and Management of Educational Institutions, Zhytomyr Ivan Franko State \\ University, Ukraine \\ ${ }^{2}$ The National University of Ostroh Akademy, Ukraine \\ ${ }^{3}$ Department of English Language, Zhytomyr Ivan Franko State University, Ukraine \\ ${ }^{4}$ Department of Management and Educational Technology, National University of Life and Environmental Sciences of Ukraine, \\ Ukraine \\ ${ }^{5}$ Department of Theory and Methods of Preschool Education, Municipal Institution "Kharkiv Humanitarian-Pedagogical Academy" of \\ Kharkiv Regional Council, Ukraine \\ ${ }^{6}$ Department of Pedagogy and Psychology of Preschool Education and Children's Creativity, National Pedagogical University named \\ after M.P. Drahomanov, Ukraine \\ ${ }^{7}$ Rector of Khmelnytskyi Humanitarian-Pedagogical Academy, Khmelnytskyi, Ukraine \\ ${ }^{8}$ Department of Foreign Languages, Bohdan Khmelnytskyi National Academy of the State Border Guard Service of Ukraine, \\ Khmelnytskyi, Ukraine
}

Received October 12, 2020; Revised November 18, 2020; Accepted December 13, 2020

\section{Cite This Paper in the following Citation Styles}

(a): [1] Olena Miroshnychenko, Igor Pasichnyk, Alexander Voznyuk, Serhii Kubitskyi, Marina Roganova, Hanna Tsvietkova, Inna Shorobura, Ihor Bloshchynskyi, "Study of Ukrainian Polar Explorers' Psychological Readiness for Extreme Environments at the Antarctic Station," International Journal of Human Movement and Sports Sciences, Vol. 8, No. 6, pp. 455 - 461, 2020. DOI: 10.13189/saj.2020.080618.

(b): Olena Miroshnychenko, Igor Pasichnyk, Alexander Voznyuk, Serhii Kubitskyi, Marina Roganova, Hanna Tsvietkova, Inna Shorobura, Ihor Bloshchynskyi (2020). Study of Ukrainian Polar Explorers' Psychological Readiness for Extreme Environments at the Antarctic Station. International Journal of Human Movement and Sports Sciences, 8(6), 455 - 461. DOI: 10.13189/saj.2020.080618.

Copyright $₫ 2020$ by authors, all rights reserved. Authors agree that this article remains permanently open access under the terms of the Creative Commons Attribution License 4.0 International License

\begin{abstract}
The research is devoted to the study of Ukrainian polar explorers' psychological readiness for extreme environments of the "Academician Vernadsky" Antarctic station. The relevance of the study is substantiated; the scientific papers of domestic and foreign researchers on the problem concerned are analyzed. The concept of psychological readiness for extreme environmental conditions is specified; the age limits of the studied groups are determined; methodological tools of psychological research are presented. Theoretical bases and practical results on the problem involved are considered. The three aspects of readiness of the polar explorers, namely psychophysiological, personality, social-psychological are differentiated. The peculiarities of psychological training are described. The complex of methods of psychological research of three age categories
\end{abstract}

is implemented. The comparison of the results of the research has revealed some changes in psychological characteristics. It is proved that the most prepared age group includes middle-aged persons (from 35 to 45 years), which constitutes about $40 \%$ of the participants and indicates a sufficient level of psychological stability of wintering teams. These results enable to identify new criteria for psychological prediction, as well as to confirm the need for further psychological research.

Keywords Psychological Readiness for Extreme Environmental Conditions, Polar Explorers, Living in Antarctic Conditions, Training for Extreme Activities, Age Groups of Adulthood 


\section{Introduction}

Ukraine being one of the 29 countries having the status of a Consultative Party to the Antarctic Treaty explores the "White Continent" on the Ukrainian Antarctic Station "Academician Vernadsky". Extreme conditions and a long stay of 12-13 months in an isolated area with harsh climatic conditions have a significant impact on the readiness of the station crew. These factors determine the relevance of the article.

The researchers of the peculiarities of activity in extreme environmental conditions distinguish in the phenomenon of readiness the following aspects: physical fitness, neurodynamic fitness, psychological readiness, one of which, depending on specific factors, may become the leading one. On the other hand, the readiness to act in extreme conditions is closely related to the adaptive capabilities of the individual, manifested in various types of adaptation (physiological, biological, psychological, social) (Moiseyenko, et al, 2016).

Adaptation/adjustment is understood as a complex and multilevel phenomenon of a person's inclusion in a micro-and macro-living environment. Based on the research of A. Nalchadjian, we proceed from the assumption that a well-adapted person is a person having a positive social experience, optimal professional productivity, mental balance and willingness to work even in harsh conditions (Nalchadjian, 1985).

A group of scientists (physicians, physiologists, psychologists) of the National Antarctic Research Center has been dealing with the problem of Ukrainian polar explorers' psychological readiness for extreme environmental conditions for a long time. These scientists have proved that adaptation during the winter period depends on how polar explorers are ready for life in such conditions since their activity is connected with the influence of numerous extreme factors (the peculiarities of regional photoperiodic, time zone shift, sensory deprivation, meteorological and heliophysical phenomena, etc.), which creates an additional burden on the functional systems of a person's organism (Moiseyenko, et al, 2016).

The researchers from countries with permanent Antarctic stations also note the difficulty of a person's adjusting to harsh Antarctic conditions, namely: psychophysiological adaptation depends on the level of psychological readiness to perform professional duties in difficult situations.

A lot of scientists show the impact of a set of negative factors (isolation and confinement, interpersonal relationship and adjustment to a group, monotony environment, absence of privacy and emotional satisfaction, etc.) over person's psychological variables (Nicolas, et al, 2016; Norris, 2017; Chen, et al, 2016; Mullin, 2006; Palinkas, 2003; Peri, et al, 2000). Another important negative factor is connected with light influence on the human organism (Mehlhorn, 2017) since Antarctica is characterized by 24-hours of darkness during winter/polar night (Tortello, et al, 2018).

Some authors compare extreme temperatures and tough environmental conditions in Antarctica, to some extent, an analogue of a space ship (Lugg, Shepanek, 1999; Suedfeld, Weiss, 2000). The researchers state that emotional disruptions and psychological disorders as well as mood fluctuations, anxiety, depression, anger, hostility, sleep disturbance, psychological stress, fatigue, decrease in cognitive performance (Rohan, Rough, 2017; Palinkas, Suedfeld, 2008); Harris, et al, 2010; Solanas, et al, 2016; Barbarito, et al, 2001; Khandelwal, et al, 2015).

According to our research, polar explorers' psychological readiness is based on their psychophysiological qualities. Person's psychophysiological functions in extreme conditions must meet the following requirements: high emotional stability; resistance to fatigue; clear manifestation of a strong, balanced mobile type of higher nervous activity; high rate of sensory-motor reactions, certain rate of attention vacillation; good visual and auditory memory.

Psychological readiness for this activity includes assessing capabilities in relation to prospective difficulties, as well as self-confidence and self-preparedness, purposefulness, independence in decision-making, self-control, the ability to manage emotions, etc. Independence and social experience of the individual as the components of the decision-making system in complex situations have also been confirmed by our data. We should also mention not only various conscious/unconscious settings to certain forms of response, but also awareness of the tasks, models of probable behavior, the determining of the optimal means of activity, the assessing of persons' capabilities in relation to prospective difficulties/problems.

It must be noted that the process of psychological adaptation is associated with the peculiarities of establishing social ties between members of long-term expeditions when certain regularity can be fixed: the higher the social status of a person, the better adaptation processes have been revealed (Miroshnichenko, et al, 2018).

As M. Mehta and G. Chugh have found, an important role in adapting to extreme conditions is played by such social personality traits as enthusiasm, responsibility, optimistic orientation to the future, determination and the need for self-realization (Mehta, Chugh, 2011).

The results of our theoretical analysis have showed that despite the availability of scientific research on the problem mentioned, some issues remain unexplored, including the formation of psychological readiness of Ukrainian polar explorers for their work in Antarctica.

The urgency of this problem also stems from recent tragic event occurred at the Ukrainian Antarctic station when one of its members committed suicide which, in our opinion, was due to insufficient psychological 
organization (pre-expedition training and studying the prospective members of polar station) of the last Antarctic expedition.

\subsection{The Aim}

The objective of this research is to present the theoretical foundations and practical results of the study of Ukrainian polar explorers' psychological readiness for extreme environments at the station "Academician Vernadsky".

\subsection{Tasks}

1) To clarify the concept of psychological readiness for extreme environmental conditions.

2) To determine the age limits of the experimental groups of Ukrainian polar explores.

3) To present the methodological tools of psychological research.

4) To demonstrate the results of the study of age peculiarities of psychological readiness for extreme conditions at the Antarctic station "Academician Vernadsky" applying the pertinent data of 9 Ukrainian expeditions.

\section{Materials and Methods}

\subsection{Participants}

The empirical study has been conducted in the period from 2011 to 2019. The study has involved the polar explorers who performed professional duties at the Ukrainian Antarctic Station "Academician Vernadsky" for 12-13 consecutive months. The total number of persons is 70 males, the age of the respondents ranges from 26 to 63 years.

\subsection{The Methodological Background}

The methodological foundations of the study are the psychological theory of the classics of domestic psychology, S. Rubinstein and A. Leontiev, within the personality approach to the study of psychological phenomena. This approach assumes that all mental processes, psychological properties and states belonging to a particular person depend on and are determined by his/her individual and social existence. S. Rubinstein believed that personality's orientations (attitudes, settings) are certain dynamic trends being the motives of human activity and, in turn, are determined by goals and objectives of this activity. In his view, this concept ("personality's orientation") includes two interrelated aspects that indicate the source of orientation: the subject content (semantic aspect) and tension (dynamic aspect). Considering the dynamic aspect, S. Rubinstein singles out the attitude as a special orientation on the goals/objectives of the activity, which is manifested in person's willingness to act in a certain way (refer to Payne, 2009).

A. Leontiev, developing the ideas of S. Rubinstein, has considered the core of the personality to be a system of relatively stable hierarchical motives. Some motives (meaning-forming) impart the activity with individual sense and a certain direction, while others play the role of motivating factors, which serves as a basis for personality's readiness for activity (Leontiev, 2009). Some scholars Heildenberg C. Dimarucot and Gil P. Soriano used in their study Physical Activity Readiness Questionnaire+ and assessed cardiovascular endurance through volume of oxygen uptake or VO2 max before and after the multistage training program. They collected profile of the subjects which includes the age in years, sex, height in centimeters, weight in kilograms, and resting heart rate (bpm) (Dimarucot, Soriano, 2020). Other scholars, such as Faruk Salih Şeker and Mehmet Şahin prepared the questionnaire with 26 questions, four questions are intended to examine the biographical features, four are intended to examine the characteristics game, and the remaining 18 are intended to examine the effects on social morality (Şeker, Şahin (2020).

\subsection{The Methods Used}

To determine the polar explorers' psychological readiness for extreme conditions, we have used the methods enabling to study such personality aspects of psychological readiness as personality's orientation to activity (the "Orientation Questionnaire" by B. Bass (Bass, 1962) and socio-psychological attitudes to activity (the "Diagnosis of socio-psychological attitudes personality by O. Potemkina (Potemkina, 2004). The results obtained were confirmed by the use of an auxiliary method interviews with the respondents. The application of these methods has ensured the reliability and validity of our study. The latter has been conducted within the psychological training of wintering personnel for life in the Antarctic being one of the activities of the medical and biological laboratory of the National Antarctic Research Center of Ukraine.

\section{Results}

We define a person's psychological readiness for life in extreme conditions as a state of mobilization of all psychophysiological systems of the body, ensuring the effective implementation of necessary actions. Psychological readiness, being a functional state, is primarily determined by stable individual and mental characteristics inherent in the personality. This state, according to our data, includes motivational, orientational, operational, volitional and evaluative components. Psychological readiness is a relatively stable state, which is determined by the basic (including characterological) 
and programmable (motivational and intellectual) personality traits, and is manifested in an active-positive attitude to the profession, and by formed professional self-consciousness. Therefore, the study of a person's psychological readiness to work in extreme conditions is aimed at identifying his/her certain professionally important qualities and abilities, which realize the following characteristics:

- positive attitude to the type of activity;

- the need for a certain special activity, interest and inclination to the activity, conscious motivation of the personality, and internal acceptance of the requirements of the activity in extreme conditions;

- personality's awareness of social significance of the activity;

- motivational component of personality's activity, desire for self-education and self-improvement.

We distinguish the following aspects of personality's readiness: psychophysiological, personalitypsychological, socio-psychological being dialectically united and sharing their peculiar qualities. In this article, we present only the part of our research, which relates to the personality aspect of psychological readiness to work in extreme conditions.

As our experience has shown, the most favorable polar explorer's state at the beginning of the expedition is the state of personality-psychological ("combat”) readiness. This state is characterized by the following features: general emotional uplift, vigor, inspiration, inner composure and concentration, self-confidence, exacerbation of the processes of perception, attention, thinking, memory, imagination and representations (Miroshnichenko, et al, 2018).

The dynamics of polar explorers' personality-psychological readiness to perform professional duties in extreme conditions is one of the most important tasks of psychological support of pre-expedition training, the quality of which significantly affects the full realization of professionals' potential.

On the eve of a long, responsible and rather complex trip, which lasts up to 10-12 days and runs through 3-5 countries, the polar explorers' psychological readiness to their prospective work is unstable due to their increased sensitivity to various factors influencing both external and internal content of their psychic. Such factors, first of all, are difficult crossings to the location of the Antarctic station (planes, buses, sea ships), long stay in an unfamiliar socio-cultural environment, unusual level of organization of accommodation and food, close interaction of the members of the expedition and constant control by leadership, increased mental/emotional stress, the negative impact of time zone changes, "seasickness", etc. The combination of these factors can have a significant impact on functional systems of human organism, its adaptation processes, which may prevent maximum activation of organism's resources, affecting the quality of polar explorers' psychological states. Therefore, psychological training plays an important role to prevent negative aspects mentioned above.

The activity of polar explorers is determined by a complex combination of external and internal psychological qualities. They are clarified by the researchers at a specially organized meeting, through a long communication between the researchers and the candidates for the expedition, which takes place in conditions socially and psychologically close to the conditions of the expedition: the team members abide in a separate house in a closed area. In such conditions, prospective polar explorers are tested for psychological compatibility, the ability to perform different professional duties (a mechanic, doctor, cook, etc), the skills to work together and spend leisure time in a closed team, and so on. During the meeting, the psychologist conducts psychological examinations, namely: observations, individual conversations, business games, testing with the help of different tools and techniques.

During our research, we have come to a conclusion that there are objective and subjective difficulties in preparing for work in extreme conditions. Objective difficulties are caused by the peculiarities of living conditions, and subjective ones are connected with the peculiarities of the personality of a polar explorer. For rigorous expedition conditions and coexistence in a closed team, the following personality traits play an important role: purposefulness and persistence; endurance and self-control; determination and courage; initiative and discipline.

We have also found that adaptation to harsh conditions in Antarctica depends, to some extent, on the age characteristics of wintering participants. For experimental verification of our observations, we have divided the winterers of each expedition into age groups: 22-34 years (31 persons), 35-45 years (25 persons), older than 45 years (14 persons).

This distribution is due to some data presented in the works of domestic scientists who propose the selection of the following periods in adulthood: the period of youth (from 21 to 28 years), young adulthood (28-34 years), adulthood (35-45 years), maturity (46-55 years), late maturity (56-66 years), aging period (66-78 years), old age $(78+$ years $)$. In this respect, K. Krutiy and L.Zdanevych have put forward the age periodization being based on the theory of generations, according to which the adults are divided into age groups depending on the year of birth: born in 1947-1967 - the generation of "Baby Boomers", born after the Second World War (in our study they are the polar explorers of 46-62 years old); 1968-1987 - "the Generation "X" or "Unknown Generation" (in our study these are persons of 35-45 years old); 1988-2000 - the "Generation "Y" or "the Generation Millennium" (in our study they are polar explorers of 22-34 years old) (Krutiy, Zdanevich, 2017).

Our research has presupposed using several methods the first of which is the study of personality orientations (B. Bass). Table 1 presents the indicators of relevant types 
of personality orientation in the representatives of different age groups.

As you can see from the table, the representatives of the older group of winterers (14 people aged from 46 to 62 years) are dominated by orientation on work, and the percentage of orientation on oneself is the lowest in all groups. The representatives of the middle age group (25 people aged from 35 to 45 years) demonstrate the similar order and the distribution with that of the older group, although all indicators are higher comparing with the older group. This testifies to a greater activity of representatives of "the Generation X" compared with the senior group. The younger age group is made up of 31 persons between 22 and 34, and this group also prefers to focus on work, the second place is the focus on oneself, and the last is the focus on the team. This indicates, in our opinion, that the younger generation has a more pronounced individualism, expressing the selfishness of youth, the desire to be original, unique. The influence of social changes in society also plays a certain role: after all, individualism, entrepreneurship, and individual activity are dynamically developing in modern society.

The next method used presupposes the study of personality's socio-psychological setting in motivation and need sphere. It is these settings that encourage the participants of Ukrainian Antarctic expeditions to work in extreme conditions. Here we have applied O. Potemkina's method, presupposing taking into consideration such continuums as "altruism-egoism", "process-result", and "freedom-power". This method helps to study the state of psychological readiness formed on the basis of personality experience and has a direct impact on possible reactions of a personality. Here we have the psychological readiness for a certain behavior in specific situations (Potemkina, 2004).

The results of the study are presented in table 2 .

After analyzing the data according to method used, we can draw the following conclusions. Among the representatives of the older generation of polar explorers, the main setting, which we interpret as psychological readiness to meet current needs, is the settings to work, altruism and freedom. The indicator of setting to egotism is the lowest among all groups. Such settings are the result of social upbringing of "the Children of Winners" generation, their activities are conditioned by the needs and ideals of the time of their youth. The representatives of the medium group of polar explorers have demonstrated the highest indicators of settings to freedom (the highest indicator of all groups being the sign of time spirit of their youth), to work and to the result of their activities. The lowest value is the setting to money: this is ample evidence that this group consists of the largest number of romanticists who go on an expedition for new experiences thus expressing the striving to cognize new horizons of outer and inner reality. The representatives of the younger group have the largest percentage of the settings to the result of activity, freedom and process. The representatives of "the Generation $\mathrm{Y}^{\text {" express the desire to }}$ act freely and reach a result. They have the highest indicators of settings towards selfishness and money compared with other groups, which is the spirit of contemporary society.

Table 1. The results of the study of personality orientation in representatives of different age groups

\begin{tabular}{|c|c|c|c|c|c|c|}
\hline \multirow{2}{*}{ Orientation } & \multicolumn{2}{|c|}{ Senior group of polar explorers } & \multicolumn{2}{c|}{ Medium group of polar explorers } & \multicolumn{2}{c|}{ Junior group of polar explorers } \\
\cline { 2 - 7 } & $\begin{array}{c}\text { average } \\
\text { points in } \\
\text { the group }\end{array}$ & $\begin{array}{c}\text { percentage of the } \\
\text { maximum number of } \\
\text { points on the scale }\end{array}$ & $\begin{array}{c}\text { average } \\
\text { points in } \\
\text { the group }\end{array}$ & $\begin{array}{c}\text { percentage of the } \\
\text { maximum number of } \\
\text { points on the scale }\end{array}$ & $\begin{array}{c}\text { average } \\
\text { points in } \\
\text { the group }\end{array}$ & $\begin{array}{c}\text { percentage of the } \\
\text { maximum number of } \\
\text { points on the scale }\end{array}$ \\
\hline Self-centered & 8.1 & $\mathbf{3 3 . 8}$ & 9.1 & $\mathbf{3 7 . 9}$ & 10.0 & $\mathbf{4 1 . 7}$ \\
\hline Teamwork & 10.9 & $\mathbf{4 5 . 4}$ & 11.5 & $\mathbf{4 7 . 9}$ & 9.4 & $\mathbf{3 9 . 2}$ \\
\hline Work-oriented & 11.9 & $\mathbf{4 9 . 6}$ & 12.2 & $\mathbf{5 0 . 8}$ & 11.1 & $\mathbf{4 6 . 3}$ \\
\hline
\end{tabular}

Table 2. Results of the study of personality's socio-psychological settings in motivational-needs sphere in the representatives of different age groups

\begin{tabular}{|c|c|c|c|c|c|c|}
\hline \multirow{2}{*}{$\begin{array}{c}\text { Socio-psycholo } \\
\text { gical settings } \\
\text { based on: }\end{array}$} & \begin{tabular}{c} 
Senior group of polar explorers \\
\cline { 2 - 7 } \\
points in the \\
group
\end{tabular} & $\begin{array}{c}\text { percentage of the } \\
\text { maximum number of } \\
\text { points on the scale }\end{array}$ & $\begin{array}{c}\text { Medium group of polar explorers } \\
\text { average } \\
\text { points in the } \\
\text { group }\end{array}$ & $\begin{array}{c}\text { percentage of the } \\
\text { maximum } \\
\text { number of points } \\
\text { on the scale }\end{array}$ & $\begin{array}{c}\text { Junior group of polar explorers } \\
\text { average points } \\
\text { in the group }\end{array}$ & $\begin{array}{c}\text { percentage of the } \\
\text { maximum } \\
\text { number of points } \\
\text { on the scale }\end{array}$ \\
\hline result & 6.8 & 68 & 6.7 & 67 & 7.1 & 71 \\
\hline work & 7.8 & 78 & 6.9 & 69 & 5.6 & 56 \\
\hline process & 6.6 & 66 & 7.2 & 72 & 6.6 & 66 \\
\hline freedom & 7.2 & 72 & 8.1 & 81 & 7.1 & 71 \\
\hline altruism & 7.6 & 76 & 6.6 & 66 & 6.0 & 60 \\
\hline power & 4.5 & 45 & 4.0 & 40 & 3.8 & 38 \\
\hline egotism & 2.6 & 26 & 4.1 & 41 & 4.5 & 45 \\
\hline money & 2.8 & 28 & 2.2 & 22 & 4.2 & 42 \\
\hline
\end{tabular}




\section{Conclusions}

Studies of polar explorers' personality and psychological characteristics occupy key positions in the researches on extreme activities and make up the basis for predicting the actualization of person's psychological readiness for life in the conditions of social isolation and permanent influence of extreme environmental factors, which are characteristic of harsh Antarctica.

Taking into account the defined indicators, we can draw conclusions about psychological readiness of the candidates for participants in winter expeditions for Antarctica. Preference must be given to the candidates who have indicators of a strong, balanced nervous system, expressing the professional and social orientation and attitude to the activities that contribute to more efficient adaptation for the conditions of Antarctic station and to more effective performance of professional activities.

The results of our study have shown that the indicators of polar explorers' psychological readiness for life in the Ukrainian Antarctic station "Academician Vernadsky" are most pronounced in the age from 35 to 45 years. The representatives of this group make up about $40 \%$ of the participants of the Ukrainian Antarctic expeditions, which indicates sufficient level of psychological stability of wintering teams. Thus, it can be argued that Ukrainian winterers are generally ready to live at the Antarctic station (in the personality and psychological aspect), having differences in different age groups in the spheres of orientation and attitudes to the activities, which creates a unique combination of youth, adulthood and maturity.

Prospects for further research lie in developing a typology of the personality of the Ukrainian polar explorer, taking into consideration his individual-typological features, as well as motivation to work in extreme conditions.

\section{REFERENCES}

[1] Bakhmutova, L. (2019). Factors and models of interpersonal interaction of participants in long-term Ukrainian Antarctic Expeditions. Fundamental and applied researches in practice of leading scientific schools. Ottawa, Ontario, Canada, 36(6), 48-55. http://dx.doi.org/10.33531/farplss.2019.6.6

[2] Barbarito, M, Baldanza, S, Peri, A (2001). Evolution of the coping strategies in an isolated group in an Antarctic base. Polar record, 37(201), 111-120. http://dx.doi.org/10.1017/S 0032247400026930

[3] Bass, B.M. (1962). The Orientation Inventory. Palo Alto, CA: Consulting Psychology Press.

[4] Chen, N., Wu, Q., Li, H., Zhang, T., Xu C. (2016). Different adaptations of Chinese winter-over expeditioners during prolonged Antarctic and sub-Antarctic residence. International journal of biometeorology, 60(5), 737-747. http://dx.doi.org/10.1007/s00484-015-1069-8
[5] Dimarucot, H. C., Soriano, G. P. (2020). Effectiveness of the Multistage Jumping Rope Program in Enhancing the Physical Fitness Levels among University Students. International Journal of Human Movement and Sports Sciences, 8(5), 235 - 239. DOI: 10.13189/saj.2020.080511.

[6] Harris, A., Marquis, P., Eriksen, H.R., Grant, I., Corbett, R. (2010). Diurnal rhythm in British Antarctic personnel. Rural Remote Health 10(2), 1351.

[7] Khandelwal, S, Bhatia A, Mishra AK (2015). Psychological health in the summer team of an Indian expedition to Antarctica. Journal of Mental Health and Human Behaviour 20(2), 65-70.

[8] Krutii, K. L., Zdanevych, L. V. (2017). Review of empirical research on the stratification of modern preschool childhood. Development and modernization of social sciences: experience of Poland and prospects of Ukraine. Lublin: Izdevnieciba «Baltija Publishing», 56-71.

[9] Leontiev, A. N. (2009). The Development of Mind. Pacifica, CA: Marxist Internet Archive Publications.

[10] Lugg, D., Shepanek, M. (1999). Space analogue studies in Antarctica. Acta Astronautica, 44(7-12), 693-699. http://dx.doi.org/10.1016/S0094-5765(99)00068-5

[11] Mehlhorn, B., Mehlhorn, H. (2017). Antarctica: The peculiar world. Biodiversity and Evolution of Parasitic Life in the Southern Ocean, Springer, 7-12. http://dx.doi.org/10.1007/9 78-3-319-46343-8_2

[12] Mehta, M., Chugh, G. (2011). Achievement Motivation and Adjustment in Members of Indian Scientific Expedition to Antarctica. Psychological Studies, 56(4). http://dx.doi.org/1 0.1007/s12646-011-0109-7

[13] Miroshnichenko, O.A., Gutsulyak, O.P. \& Marchenko, O.V. (2018). Introduction of diagnostic procedures and training programs in psychological training and rehabilitation of winterers. Ukrainian Antarctic Journal, 16, 178-187.

[14] Moiseyenko, E., Sukhorukov, V., Pyshnov, G., Mankovska, I., Rozova, K., Miroshnichenko, O. (2016). Antarctica challenges the new horizons in predictive, preventive, personalized medicine: preliminary results and attractive hypothesis for multidisciplinary prospective studies in the Ukrainian «Akademician Vernadsky» station. EPMA Journal,7(1), 11

[15] Mullin, J.R. (2006). Some psychological aspects of isolated Antarctic living. American Journal of Psychiatry 117(4), 323-325. http://dx.doi.org/10.1176/ajp.117.4.323

[16] Nalchajyan, A. A. (1985). Personality. Group socialization and mental adaptation; Academy of Sciences of the ArmSSR, Institute of Philosophy and Law, 263, p. 21, Yerevan Publishing House of the Academy of Sciences of the ArmSSR.

[17] Nicolas, M., Suedfeld, P., Weiss, K., Gaudino, M. (2016). Affective, social and cognitive outcomes during a 1-year wintering in Concordia. Environment and Behavior 48(8), 1073-1091. http://dx.doi.org/10.1177/0013916515583551

[18] Norris, N. (2017.) Play building as qualitative research: A participatory arts-based approach. Routledge, USA.

[19] Palinkas, L.A. (2003). The psychology of isolated and confined environments: Understanding human behavior in 
Antarctica. American Psychologist 58(5), 353-363. http://dx.doi.org/10.1037/0003-066X.58.5.353

[20] Palinkas, L.A., Suedfeld, P. (2008). Psychological effects of polar expeditions. Lancet 371(9607), 153-163. http://dx.doi.org/10.1016/S0140-6736(07)61056-3

[21] Payne, T. R. (1969). S. L. Rubinštejn and the philosophical foundations of Soviet psychology. New York: Humanities Press. http://dx.doi.org/10.1007/978-94-010-3456-2

[22] Peri, A., Scarlata, C., Barbarito, M. (2000). Preliminary studies on the psychological adjustment in the Italian Antarctic summer campaigns. Environment and Behavior 32(1), 72-83. http://dx.doi.org/10.1177/0013916002197243 2

[23] Potemkina, O. F. (2004). The psychology of individuality, Moscow: AST Press.

[24] Rohan, K.J., Rough, J.N. (2017). Seasonal affective disorder. The Oxford Handbook of Mood Disorders.

[25] Sannikov, O. (2016). Information system operator: the structure and components of personal choice. Science and
Education. Psychology: 7/CXXXVIII, 133-143. http://dx.doi.org/10.24195/2414-4665-2016-7-22

[26] Şeker, F. C., Şahin, M. (2020). Comparison of the Opinions of Citizens and Professional Soccer Players about Betting and Match Fixing. International Journal of Human Movement and Sports Sciences, 8(4), 110 - 116. DOI: 10.13189/saj.2020.080402.

[27] Solanas, A., O’Neill, B.V., Morris, T.E., Dunbar, J. (2016) Physiological and cognitive responses to an Antarctic expedition: A Case Report. International Journal of Sports Physiology and Performance, 11(8), 1053-1059.

[28] Suedfeld, P., Weiss, K. (2000). Antarctica: Natural laboratory and space analogue for psychological research. Environmental Behavavior 32(1), 7-17.http://dx.doi.org/10. 1177/00139160021972405

[29] Tortello, C., Barbarito, M., Cuiuli, J. M., Golombek, D., Vigo D. E., Plano S. (2018). Psychological Adaptation to Extreme Environments: Antarctica as a Space Analogue. Psychology and Behavioral Science International Journal, 9(4), 555768. DOI: 10.19080/PBSIJ.2018.09.555768. 